\title{
Taurine Measurement
}

National Cancer Institute

\section{Source}

National Cancer Institute. Taurine Measurement. NCI Thesaurus. Code C122154.

The determination of the amount of taurine present in a sample. 